Article

\title{
Thermal Analysis and Improvements of the Power Battery Pack with Liquid Cooling for Electric Vehicles
}

\author{
Bizhong Xia ${ }^{1}$, Yifan Liu ${ }^{1, *}$, Rui Huang ${ }^{1}$, Yadi Yang ${ }^{1}$, Yongzhi Lai ${ }^{2}$, Weiwei Zheng ${ }^{2}$, \\ Huawen Wang ${ }^{2}$, Wei Wang ${ }^{2}$ and Mingwang Wang ${ }^{2}$ \\ 1 Graduate School at Shenzhen, Tsinghua University, Shenzhen 518055, China \\ 2 Sunwoda Electronic Co. Ltd., Shenzhen 518108, China \\ * Correspondence: liuyf17@mails.tsinghua.edu.cn; Tel.: +86-185-6565-3476
}

Received: 28 June 2019; Accepted: 5 August 2019; Published: 7 August 2019

check for updates

\begin{abstract}
In order to ensure thermal safety and extended cycle life of Lithium-ion batteries (LIBs) used in electric vehicles (EVs), a typical thermal management scheme was proposed as a reference design for the power battery pack. Through the development of the model for theoretical analysis and numerical simulation combined with the thermal management test bench, the designed scheme could be evaluated. In particular, the three-dimensional transient thermal model was used as the type of model. The test result verified the accuracy and the rationality of the model, but it also showed that the reference design could not reach the qualified standard of thermal performance of the power battery pack. Based on the heat dissipation strategy of liquid cooling, a novel improved design solution was proposed. The results showed that the maximum temperature of the power battery pack dropped by $1{ }^{\circ} \mathrm{C}$, and the temperature difference was reduced by $2{ }^{\circ} \mathrm{C}$, which improved the thermal performance of the power battery pack and consequently provides guidance for the design of the battery thermal management system (BTMS).
\end{abstract}

Keywords: power battery pack; thermal management system; liquid cooling; thermal analysis; improvement

\section{Introduction}

With the energy crisis and environmental pollution intensifying, new energy vehicles have now replaced the traditional internal combustion engine vehicles on the historical stage [1,2]. Among them, electric vehicles (EVs) have ushered in tremendous development due to the advantages of high energy utilization and zero emissions of Lithium-ion batteries (LIBs). The performance of EVs is limited by the specific energy and the safety of the battery, and these two restrictions are mainly determined by the battery temperature [3-5]. Under low-temperature conditions, the discharge capacity of the battery decays rapidly with the decrease of temperature, thereby shortening the cruising range of EVs. Under high-temperature conditions, the battery activity is enhanced, and irreversible chemical reaction may occur, causing thermal runaway and even ignition and explosion of the vehicle. When the temperature difference increases, a local hot zone is formed, resulting in a shortened battery cycle life.

Generally, in order to ensure the safety and the cycle life of LIBs, it is necessary to control the battery temperature within a reasonable range and maintain a relatively uniform temperature distribution during operation. Therefore, it is necessary to apply the battery thermal management system (BTMS) in a power battery pack [6-10]. There are two mainstream cooling methods for battery thermal management systems currently used in vehicles, namely, air cooling and liquid cooling. As the research progresses further, some new cooling methods have been tried in power battery packs, such as heat pipes [11-13], phase change material cooling [14-16], and thermoelectric cooling [17-19]. 
Air cooling can be divided into passive cooling and active cooling. At present, the mainstream heat dissipation method is active cooling, which generates a forced air flow through fans to strengthen airflow, thereby absorbing the heat of the battery. Liu et al. [20] established a mathematical model that reflected heat transfer and fluid motion of the battery and studied the effects of three variables: air duct angle, minimum end width of the air duct, and adjacent cell spacing on the air-cooled battery pack. The results showed that the temperature uniformity of the LIBs was improved with the increase of any single variable, but the space volume of the battery pack was also increased, resulting in a decrease in energy density. Heesung et al. [21] designed five parallel ventilation and heat dissipation structures for the prismatic battery module, and the results by theoretical analysis and numerical simulation were compared to obtain the optimal solution. Their research can be a guide for analyzing and comparing different battery ventilation structure designs. In Ref. [22], commercial fluid dynamics (CFD) software was used to analyze the influence of air flow and cell spacing on the thermal performance of the battery module. The results showed that the $3 \mathrm{~mm}$ cell spacing and the air flow rate of $40.8 \mathrm{~m}^{3} / \mathrm{h}$ could substantially meet the requirements of maximum temperature rise, temperature uniformity of LIBs, and the power of a fan.

Although air-cooled BTMS has the advantages of low manufacturing cost, simple structure, and easy maintenance, the air-cooled system has low heat exchange capacity, thus it cannot absorb more heat generated by the power battery pack with increasing energy density. In Ref. [23], the effects of air-cooled BTMS and liquid-cooled BTMS on the thermal performance of LIBs were compared and analyzed. The results showed that the liquid-cooled BTMS had stronger heat exchange capacity than the air-cooled BTMS, contributing to the advantages of good uniform temperature distribution and low control difficulty.

Based on the size constraints and the budgetary requirements of the vehicle, the cold plate structure is widely used in liquid-cooled BTMS. Fisher et al. [24] explored the effects of three different coolant channel cross-sectional shapes-elliptical, rounded rectangle, and rounded diamond-on the thermal properties of liquid-cooled plates. Yu et al. [25] analyzed the effects of six coolant channel designs on maximum temperature, temperature difference, and temperature uniformity of multi-channel serpentine cold plates by CFD simulation. Their research can be guide to the channel design of serpentine cold plates. Huo et al. [26] designed a mini-channel cold plate structure to study the impacts of mini-channel number, flow direction, inlet flow rate, and ambient temperature on the thermal behavior of prismatic LIBs. It can be seen that the current research hotspots are more focused on the component level based on the specific power battery pack structure, especially the comparative study of different parameters of the same liquid-cooled structures or different liquid-cooled structures.

However, as far as the author is concerned, there is very little literature on the design of a practical and typical power battery pack, and they have hardly carried out real experiments to verify the results. Chung et al. [27] developed several battery pack heat dissipation structures from the pack level, and numerical results indicated that the poor thermal conductivity from the bottom of the stack to the cold plate was one of the major obstacles in achieving efficient heat dissipation, and the asymmetric design of the cell layout had negative impact on the temperature uniformity of the pack; however, this paper did not carry out corresponding experimental verification on the simulation results. Tang et al. [28] studied the effects of three different liquid-cooled heat dissipation structures on the thermal performance of the pack through numerical simulation, and the cooling performance test was also carried out on the corresponding structure, but the research object was still the cell level based on the specific power battery pack. Moreover, compared to the direct contact thermal measurement method, the literature had a large error in the experiment using the thermal imager. Yeow et al. [29] analyzed the effect of dual cold plate on the thermal behavior of indirect liquid-cooled battery pack by finite element analysis, and the results showed that the cooling capacity of the dual cold plate configuration was twice that of the single cold plate configuration. Additionally, the location of the cold plate and the coolant flow direction had great impacts on the temperature distribution of the battery pack, but the battery pack system studied in this paper had low capacity density and low 
engineering applicability. It is noted that the evaluation index of thermal performance significantly affects the structural design of the battery pack, especially for the power battery pack with engineering application value. Meanwhile, the results of numerical simulation need to be evaluated and corrected through experiments.

In this paper, a new liquid-cooled design scheme is proposed from the pack level to improve the thermal performance of the power battery pack based on the heat dissipation strategy, and the rest of this paper is arranged as follows. Section 2 introduces the details of the mathematical model and describes the heat transfer process of the power battery pack, and the geometric model of practical and typical power battery packs as well as the simplified finite element model are demonstrated. Section 3 relates to the construction and the experimental steps of the battery thermal management experimental test bench. Section 4 compares the numerical simulation and the experimental test results, verifies accuracy and rationality of the developed model, and determines the shortage of the existing design scheme. Section 5 proposes a newly improved design scheme by analyzing the heat dissipation strategy of liquid cooling. Conclusions are drawn in Section 6.

\section{Model Development}

\subsection{Mathematical Model}

LIBs are accompanied by heat generation and release during charging and discharging. Among them, the heat source $Q_{g}$ is mainly composed of four parts, namely, Joule heat $Q_{j}$, polarization heat $Q_{p}$, reaction heat $Q_{r}$, and side reaction heat $Q_{s r}$, as shown in Equation (1) [30,31]:

$$
Q_{g}=Q_{j}+Q_{p}+Q_{r}+Q_{s r}
$$

Considering that EVs are equipped with a battery management system to prevent side reaction of the battery from generating harmful combustible gas, the side reaction heat $Q_{s r}$ must be zero.

The reaction heat $Q_{r}$ is due to electrochemical reactions inside the LIBs, which can be expressed by:

$$
Q_{r}=-I T_{b} \frac{d U_{o c v}}{d T_{b}}
$$

where $I, T_{b}$, and $U_{o c v}$ denote current, temperature, and open circuit voltage, respectively.

Due to the polarization phenomenon of the LIBs, the total resistance $R_{t}$ of the battery includes two parts: ohmic internal resistance $R_{o}$ and polarization internal resistance $R_{p}$. The heat production equations can be described in Equation (3):

$$
\left\{\begin{array}{c}
Q_{j}=I^{2} R_{o} \\
Q_{p}=I^{2} R_{p}=I^{2}\left\{R_{t}-R_{o}\right.
\end{array}\right.
$$

Therefore, the heat source $Q_{g}$ during discharging can be obtained as follows:

$$
Q_{g}=I^{2} R_{t}-I T_{b} \frac{d U_{o c v}}{d T_{b}}
$$

Also, the heat generation and the transfer process of the battery can be described as the equations below, according to the law of conservation of energy:

$$
\rho_{b} c_{p, b} \frac{\partial T_{b}}{\partial t}=\nabla \cdot\left(\lambda_{b} \nabla T_{b}\right)+Q_{g}
$$

where $\rho_{b}, c_{p, b}$, and $\lambda_{b}$ are density, specific heat capacity, and thermal conductivity of the battery, respectively. 
The commercial prismatic battery module (CATL HJL, Fujian, China) is grouped by a single cell (CATL PHEV-2, Fujian, China), which has a nickel-cobalt-manganite (NCM) cathode and graphite anode with one parallel and 12 series connections in this work. The parameters of the battery module are shown in Table 1, and the real picture is shown in Figure 1.

Table 1. The parameters of the battery module.

\begin{tabular}{ccccccc}
\hline $\begin{array}{c}\text { Rated } \\
\text { Capacity (Ah) }\end{array}$ & $\begin{array}{c}\text { Rated Energy } \\
\mathbf{( k W h )}\end{array}$ & $\begin{array}{c}\text { Rated } \\
\text { Voltage (V) }\end{array}$ & $\begin{array}{c}\text { Weight } \\
\mathbf{( k g )}\end{array}$ & $\begin{array}{c}\text { Length } \\
(\mathbf{m m})\end{array}$ & $\begin{array}{c}\text { Width } \\
(\mathbf{m m})\end{array}$ & $\begin{array}{c}\text { Height } \\
(\mathbf{m m})\end{array}$ \\
\hline 37 & 1.62 & 43.8 & 11.3 & 355 & 151.5 & 108 \\
\hline
\end{tabular}
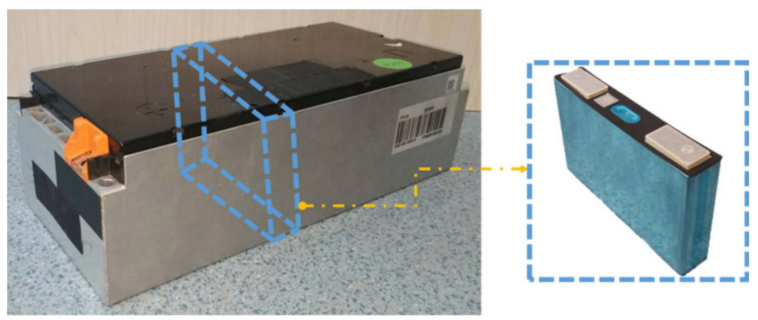

Figure 1. The real picture of the battery module.

Each substantial component on the heat transfer path of the battery, such as the battery module casing and the liquid-cooled plate, needs to satisfy the law of conservation of energy, which can be expressed as:

$$
\rho_{s} \mathcal{C}_{p, s} \frac{\partial T_{s}}{\partial t}=\nabla \cdot\left(\lambda_{s} \nabla T_{s}\right)
$$

where $\rho_{s}, c_{p, s}, \lambda_{s}$, and $T_{s}$ are density, specific heat capacity, thermal conductivity, and temperature of each substantial component, respectively.

There are boundary conditions for thermal convection between the battery and the ambient environment. According to the Newton cooling law, the convective heat transfer $Q_{a}$ can be shown as:

$$
Q_{a}=h_{a} A_{a}\left(T_{b}-T_{a}\right)
$$

where $h_{a}$ and $T_{a}$ denote the convective heat transfer coefficient and the temperature of the ambient environment, respectively; $A_{a}$ is the contact area between the battery and the environment.

Considering that the indirect liquid cooling method is adopted in this power battery pack, the natural convection heat transfer between the battery and the external environment and the radiation heat transfer (which contributes to a small proportion) can be neglected.

The laws of energy conservation, mass conservation, and momentum conservation should be satisfied in the fluid movement and the heat transfer process in the liquid-cooled plate. The expressions are as follows:

$$
\begin{aligned}
& \frac{\partial \rho_{c}}{\partial t}+\nabla \cdot\left(\rho_{c} \mathbf{V}\right)=0 \\
& \rho_{c} \mathcal{c}_{p, c}, \frac{\partial T_{c}}{\partial t}+\nabla \cdot\left(\rho_{c} \mathcal{c}_{p, c} \mathbf{V} T_{c}\right)=\nabla \cdot\left(\lambda_{c} \nabla T_{c}\right) \\
& \frac{\partial\left(\rho_{c} \mathbf{V}\right)}{\partial t}+\nabla \cdot\left(\rho_{c} \mathbf{V V}\right)=-\nabla P+\nabla \cdot(\mu \nabla(\mathbf{V}))
\end{aligned}
$$

where $\rho_{c}, c_{p, c}, \lambda_{c}$, and $T_{c}$ are density, specific heat capacity, thermal conductivity, and temperature of the cold plate, respectively; $\mathbf{V}, P$, and $\mu$ are velocity vector, static pressure, and dynamic viscosity of the coolant, respectively.

\subsection{Geometric Model}

Figure 2 shows the schematics of the structure of a practical and typical power battery pack without cover. Thermal conduction and heat capacity of the electric connections such as battery disconnect unit, battery management unit, and copper busbar for connecting battery modules are not 
considered, as those are negligible in this work. It is mainly composed of a pack lower case, battery modules, and liquid-cooled plates. Specifically, the pack is composed of 84 cells. Figure 3 shows the schematics of the structure of the coolant circulation system in the power battery pack. When the BMTS is working, the coolant flows out of the expansion kettle under the action of the water pump, flows into the entire coolant channel through the inlet pipe, flows out through the outlet pipe, enters the heat exchanger, and then recirculates to the expansion kettle, which removes the heat from the power battery pack in a timely fashion. According to the flow direction of the coolant, the battery modules are sequentially named 1 to 7 . Each cold plate is arranged directly under the battery module, and each cold plate has eight straight channels with square cross-sections, taking the cold plate directly under the battery modules 5 and 6 as an example; the cold plate structure is shown in Figure 4 .

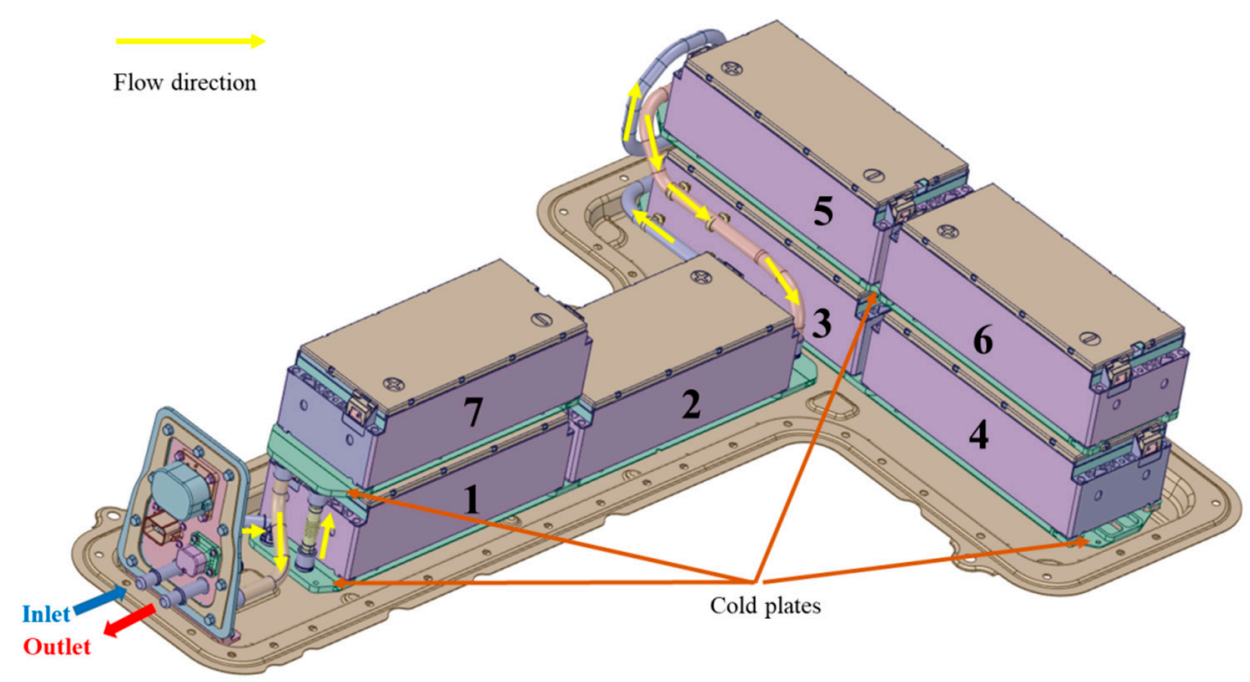

Figure 2. Structure of a typical power battery pack without cover.

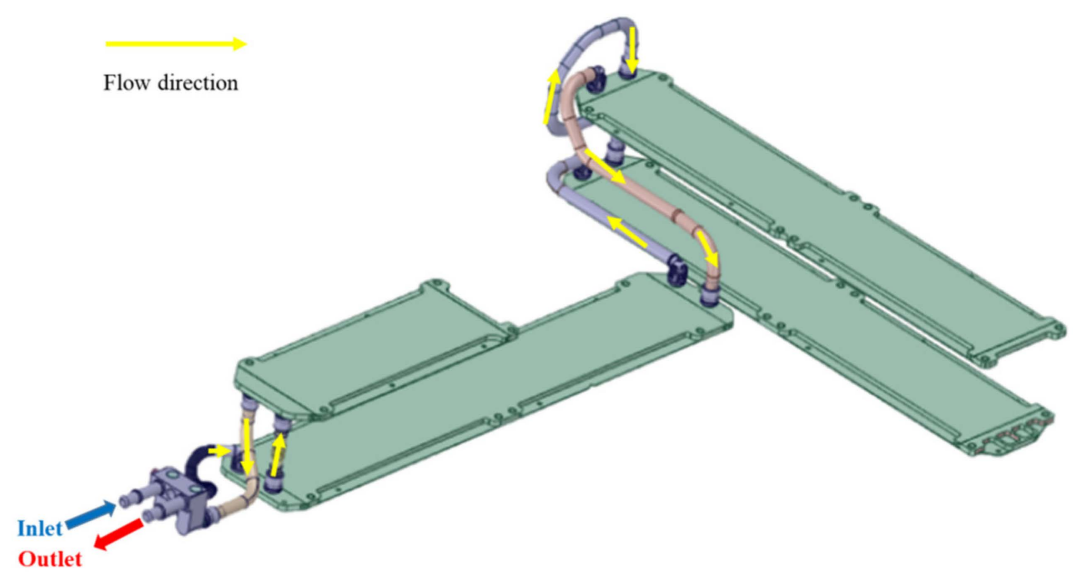

Figure 3. Structure of the coolant circulation system.

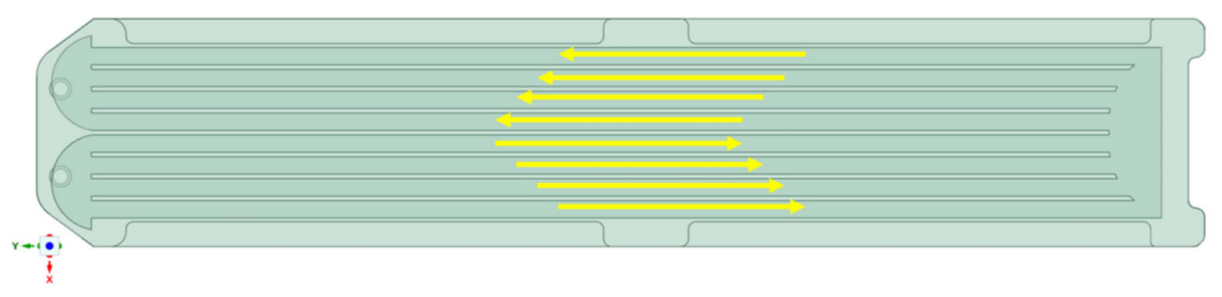

Figure 4. Outline of the cold plate structure. 
A thermal pad is placed between each of the battery modules and the liquid cooling plate to compensate for assembly errors and maintain reliable contact. In order to better monitor the thermal behavior during the operation of the power battery pack, two temperature sensors $\left( \pm 1^{\circ} \mathrm{C}\right.$ accuracy) are set in each battery module, and their positions are shown and numbered in Figure 5. T01 indicates the temperature in the center of the battery module, and T02 indicates the temperature in the edge of the battery module.

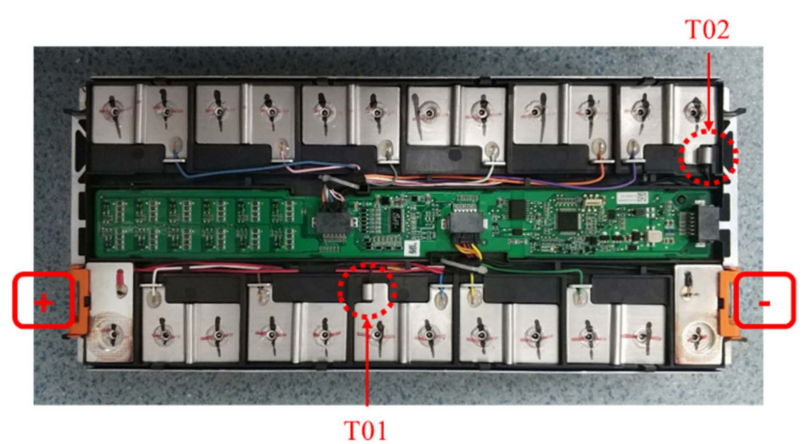

Figure 5. The position and the number of temperature sensors.

In total, there are 14 temperature sensors in the power battery pack. According to the requirements, two indicators are adopted to evaluate the thermal performance of the power battery pack; Tmax indicates the maximum temperature of the power battery pack, and $\Delta T$ shows the temperature difference inside the power battery pack. Tmax is defined as the maximum of 14 temperature measurements, and $\Delta T$ is the difference between the highest and the lowest temperatures of the 14 temperature measurements. Generally, Tmax and $\Delta T$ are limited below $45^{\circ} \mathrm{C}$ and $5{ }^{\circ} \mathrm{C}$, respectively, to reach the standard of the thermal performance of the power battery pack.

\subsection{Finite Element Model}

\subsubsection{Simplification Principle}

The schematic diagram of the heat transfer path components in the power battery pack is shown in Figure 6. Since the geometric model of the power battery pack is vast and complicated, it is necessary for it to be simplified, considering the heat transfer path. During the high-temperature cooling condition, heat is mainly generated by the battery, transferred to the thermal pad and the cold plate, and finally absorbed by the coolant. Thus, the heat transfer path is reversed in the low-temperature cooling condition.

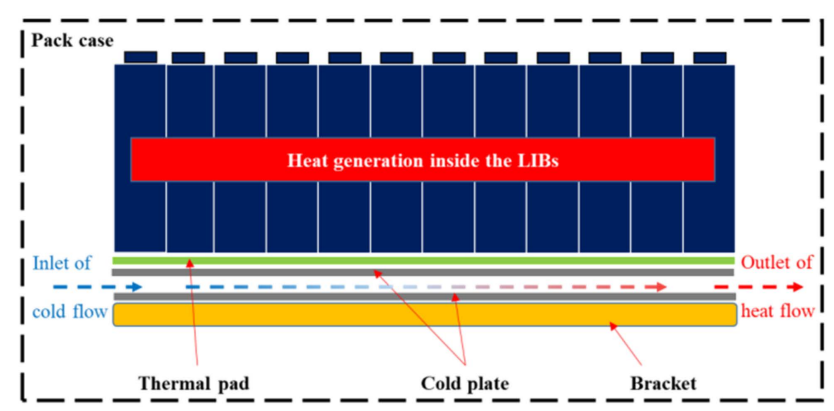

Figure 6. Schematic diagram of the heat transfer path.

\subsubsection{Parameter Configuration}

Thermal properties of all the components that need to be numerically simulated are summarized in Table 2. It is noted that, in the calculation of the subfields during the numerical simulation, the following 
assumptions are made: (1) the cold plate is filled with the coolant, which is a continuous flow of the single-phase fluid, while ignoring the inertial force and the boundary pressure of the fluid; (2) the battery is solid, containing an internal heat source, and its material is homogeneous; (3) there is no relative slip between the fluid and the solid; (4) the power battery pack is well sealed and insulated.

Table 2. Thermal properties of all the components.

\begin{tabular}{ccccc}
\hline Component & $\rho\left(\mathbf{k g} / \mathbf{m}^{3}\right)$ & $\lambda(\mathbf{W} / \mathbf{m} / \mathbf{K})$ & $c_{p}(\mathrm{~J} / \mathbf{k g} / \mathbf{K})$ & $\mu(\mathbf{P a} \cdot \mathbf{s})$ \\
\hline & & Thickness: 4 & \\
Cell & 2300 & Width: 20 & 1132 & - \\
& & Height: 13 & & - \\
Insulating film & 1200 & 0.2 & 1200 & - \\
Module case & 2702 & 180 & 903 & - \\
Thermal pad & 1200 & 2 & 1200 & - \\
Cold plate & 2702 & 180 & 903 & 0.00373 \\
Coolant & 1069.5 & 0.395 & 3341.38 & \\
\hline
\end{tabular}

Moreover, in order to evaluate whether the power battery pack can work well for a long time in the actual working process, it is necessary to select an extreme discharge condition that can generate massive heat as the evaluation condition of the BTMS. Therefore, a scheme that discharges rapidly at the end of the discharging capacity of $34 \mathrm{Ah}$ at a constant power of $30 \mathrm{~kW}$ is utilized in this paper. At the same time, a battery module is used as the test object to carry out the adiabatic discharge experiment to obtain the current data under this condition, and the heat generation can be calculated by Equation (4). The measured current data and the calculated heat generation of the battery module are shown in Figure 7.

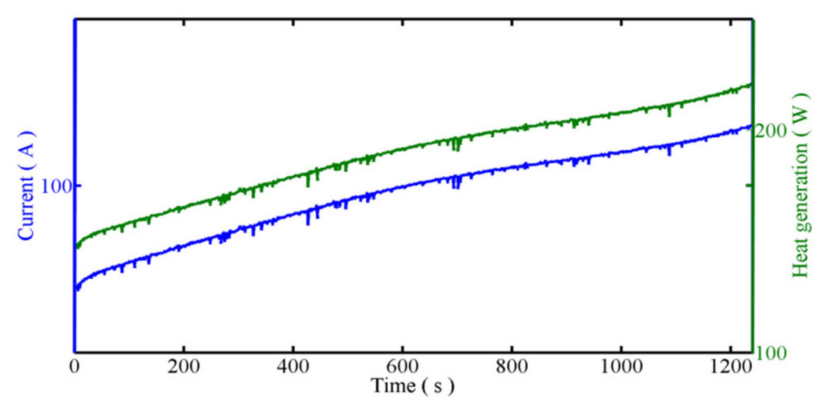

Figure 7. The measured current data and the calculated heat generation of the battery module.

Boundary conditions and initial conditions of the power battery pack should be determined. The boundary conditions of the coolant inlet and outlet are set respectively by specifying the speed value and the pressure value. Namely, the flow rate at the inlet is set to $6 \mathrm{~L} / \mathrm{min}$, and the relative static pressure at the outlet is set to zero. All other boundary conditions are set to adiabatic conditions, except no-slip boundary conditions are placed on the inner channel wall. Also, the Reynolds number of the coolant inlet is calculated to be 3291. Considering the junction between the pipe and the cold plate must be not laminar, the K-Epsilon turbulence model is used to simulate the fluid motion.

The initial temperature of the power battery pack is set to $32{ }^{\circ} \mathrm{C}$, and the coolant inlet temperature is set to $22^{\circ} \mathrm{C}$. Here, the ambient temperature outside the power battery pack is $48^{\circ} \mathrm{C}$; however, given the fact that the simulation condition is forced liquid cooling, the natural convection heat transfer between the power battery pack and the ambient environment is usually ignored.

\subsubsection{Mesh Generation}

After setting the boundary conditions and the initial conditions, the solution of Equations (5)-(8) needs to be solved by using the CFD solver. In this work, we use STAR-CCM +12.02 to generate 
5.27 million polyhedral mesh and 1.23 million prismatic mesh for power battery pack simulation to reduce the computational cost while ensuring higher simulation accuracy. The mesh and the partial enlargement of the power battery pack are shown in Figure 8. Among them, taking the cross section of the liquid-cooled plate and the fluid domain directly below the No. 2 battery module as an example, the enlarged area of the section indicates that the boundary layer mesh of the fluid-solid interface is subdivided into five layers. Moreover, it is easy to recognize the relative position of the 14 temperature sensors in the pack.

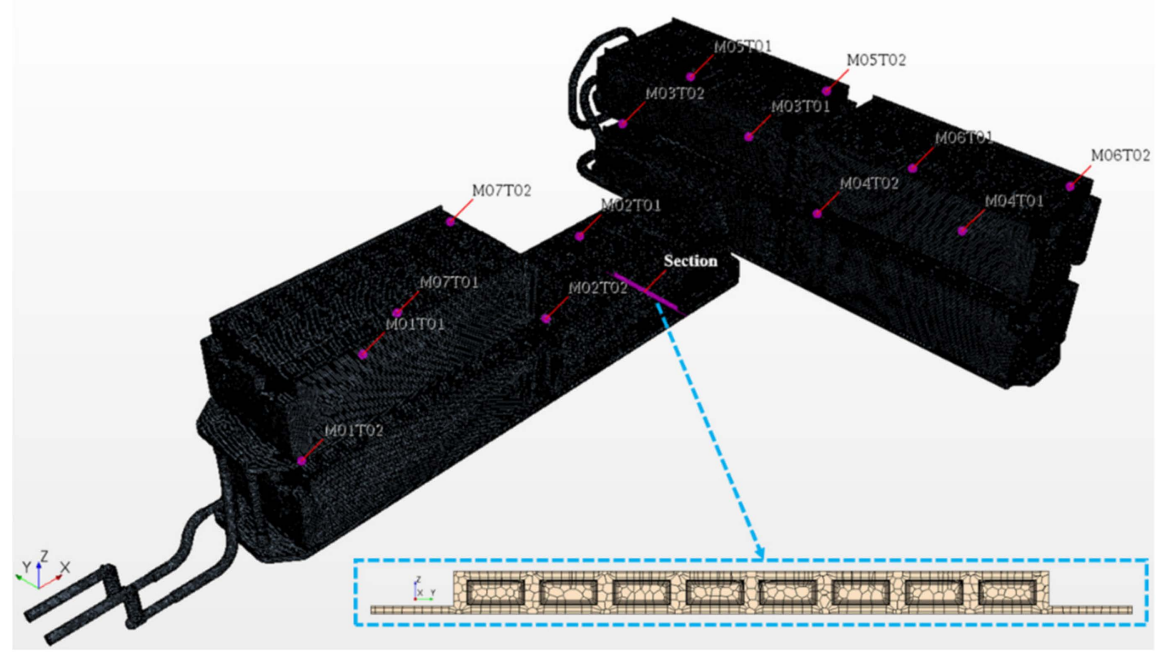

Figure 8. Mesh and partial enlargement of the power battery pack.

\section{Experiment}

The experimental apparatus used to measure the thermal performance of the liquid-cooled BTMS is shown in Figure 9. To further evaluate the thermal management reference scheme, the steps taken in this work are introduced as follows:

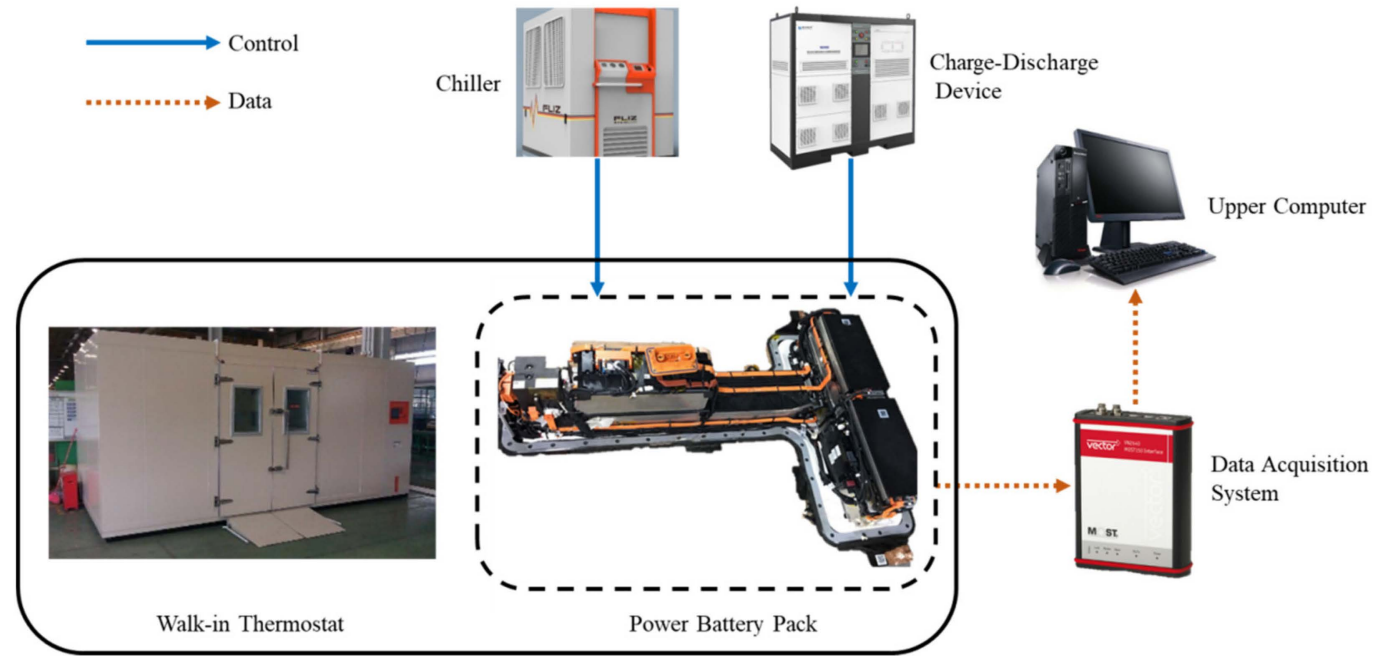

Figure 9. The overall scheme of the battery thermal management system (BMTS) test bench.

Check battery pack voltage, temperature acquisition function, and communication function of the battery management unit to ensure regular operation;

Charge the battery pack to the fully charged state using the charge/discharge device (Nebula Electronics, Fujian, China), which has several discharging modes such as constant voltage, constant current, and constant power; 
The battery pack is placed in a thermostat for four hours, whose inside temperature is $32{ }^{\circ} \mathrm{C}$, until the average temperature of the detected battery pack is in the range of $32 \pm 2{ }^{\circ} \mathrm{C}$ (namely, the obtained temperature of each temperature sensor is in the range of $30-34{ }^{\circ} \mathrm{C}$ );

Add the ethylene glycol aqueous solution to the chiller and adjust the coolant flow rate to $6 \mathrm{~L} / \mathrm{min}$ as well as the temperature to $22^{\circ} \mathrm{C}$ during internal circulation. It is noted that the temperature should be maintained at $22^{\circ} \mathrm{C}$ for one hour;

Move the battery pack in the walk-in thermostat after maintaining the temperature of the thermostat at $48{ }^{\circ} \mathrm{C}\left(48 \pm 2{ }^{\circ} \mathrm{C}\right)$, and then connect the chiller to the battery pack;

Discharge the battery pack at a constant power of $30 \mathrm{~kW}$ using the constant power discharging mode and stop working when the discharging capacity reaches the nominal capacity of $34 \mathrm{Ah}$;

Read the data recorded by the data acquisition system, which describe the temperature change of the battery pack during the discharging process, and then the data are saved by the upper computer.

\section{Results and Discussions}

The temperature distributions of the power battery pack based on the reference design are shown in Figure 10. At the end of the discharge, the temperature of the upper battery module was higher, the heat distribution of the battery module 7 was more concentrated, and the maximum temperature approximately reached $43.4^{\circ} \mathrm{C}$. On one hand, the pack was producing heat since the discharge started. As the heat generated increased, the pack temperature continued to rise until the end of the discharging process. On the other hand, the coolant temperature rose since the coolant absorbed the heat of the pack in the flow direction, which contributed to a significant decrease in the cooling capacity of the battery module. The minimum temperature of the power battery pack was about $30.1^{\circ} \mathrm{C}$. As the bottom surface of the battery module was used for heat dissipation, the bottom temperature of the battery module was colder than other areas. Through further observation, it was found that each battery module exhibited a temperature distribution with lower side temperature and higher intermediate temperature. The reason is that the battery module case was in direct contact with the cold plate on both sides, increasing thermal conductivity.

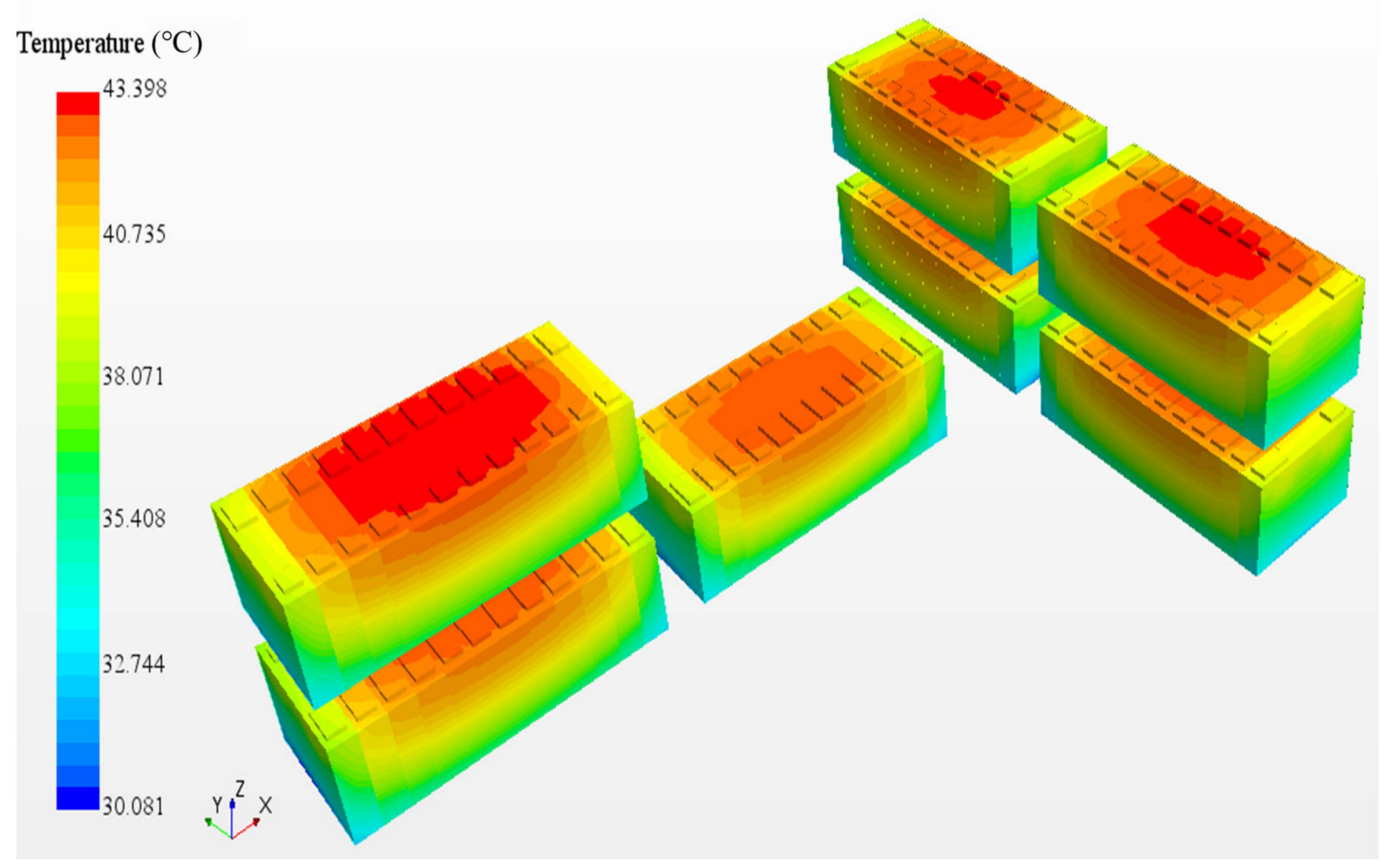

Figure 10. Simulation result at the end of test and temperature distributions of the power battery pack based on the reference design. 
The comparison of simulated temperature and experimental temperature at the temperature measurement point of the power battery pack is shown in Figure 11. There are two simulation curves and corresponding experimental measurement curves in each subgraph. As can be seen from each subgraph, these four curves all showed an upward trend and reasonable agreement. Through further observation, it was found that the initial temperature value of each simulation curve was $32{ }^{\circ} \mathrm{C}$, and the corresponding experimental initial values were not the same. Except for battery module 7, the maximum temperature of other modules did not exceed $45^{\circ} \mathrm{C}$.

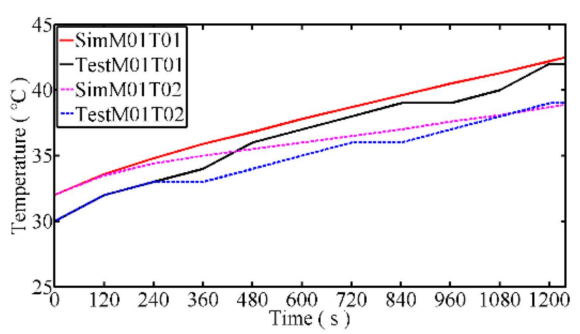

(a)

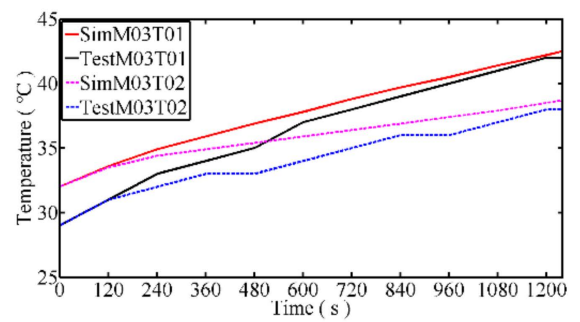

(c)

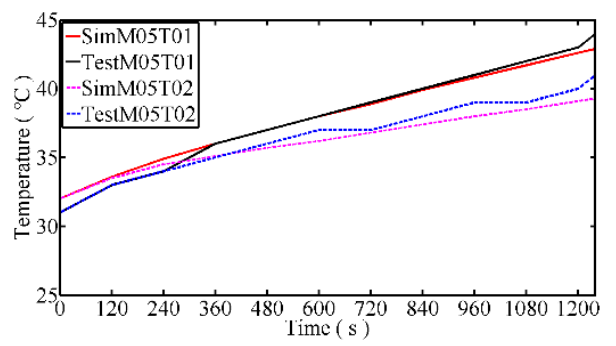

(e)

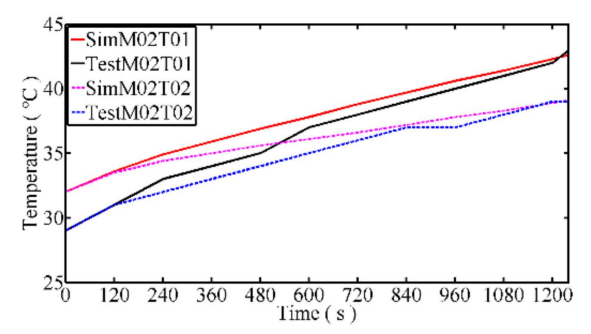

(b)

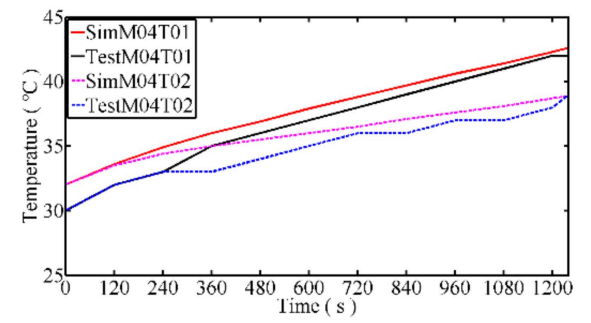

(d)

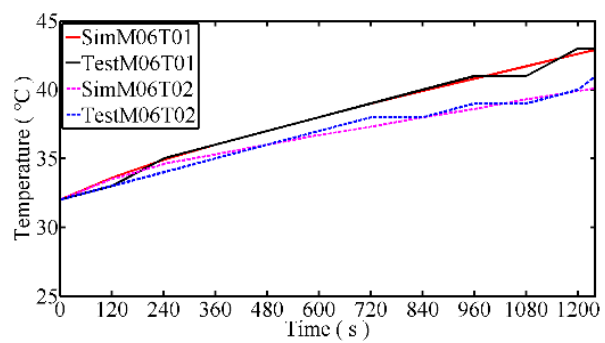

(f)

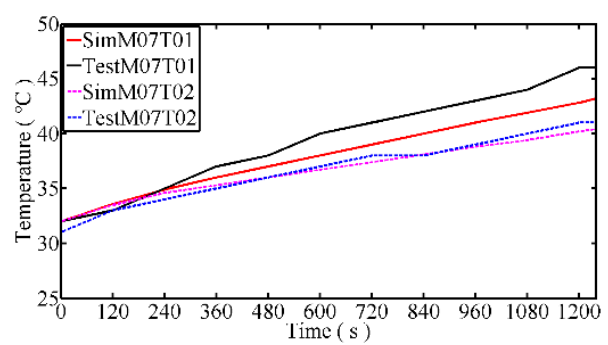

(g)

Figure 11. The comparison of simulated temperature and experimental temperature based on the temperature measurement point for each battery module: (a) Module 1; (b) Module 2; (c) Module 3; (d) Module 4; (e) Module 5; (f) Module 6; (g) Module 7.

The temperature comparison between simulation and experiment on each temperature sensor is shown in Figure 12. The maximum measured temperature of the power battery pack was $46^{\circ} \mathrm{C}$, located at the No. 1 measuring point of the battery module 7 , and the minimum temperature was $38^{\circ} \mathrm{C}$, located at the No. 2 measuring point of the battery module 3 , and the temperature difference reached $8^{\circ} \mathrm{C}$ after the discharge. Correspondingly, the maximum temperature of the numerical simulation was also located at the No. 1 measuring point of the battery module 7 , which was $43.2^{\circ} \mathrm{C}$, and the minimum 
temperature was also located at the No. 2 measuring point of the battery module 3 , which was $38.7^{\circ} \mathrm{C}$, and the temperature difference reached $4.5^{\circ} \mathrm{C}$ at the end of the discharge. Further analysis showed that the temperature maximum relative error between the experiment and the simulation of the pack was no more than $6.09 \%$. Among the whole pack, the temperature error of the battery module 7 was no more than $3{ }^{\circ} \mathrm{C}$, the temperature error of the battery module 5 was less than $2{ }^{\circ} \mathrm{C}$, and those of the other modules were no more than $1{ }^{\circ} \mathrm{C}$. Possible reasons for these errors are as follows:

(1) In the numerical simulation, the power battery pack was simplified based on the heat transfer path, and the effects of natural convection and radiation heat transfer were not considered;

(2) The thermal properties of each component were treated as constants, but these parameters changed with temperature;

(3) During the experiment, there were some unavoidable errors with the use of the equipment. For example, we could not keep the coolant flow rate to $6 \mathrm{~L} / \mathrm{min}$ or the temperature to $22{ }^{\circ} \mathrm{C}$ all the time, and the errors of the temperature sensors were $\pm 1^{\circ} \mathrm{C}$. Besides, it was challenging to maintain the same initial temperature of the power battery pack.

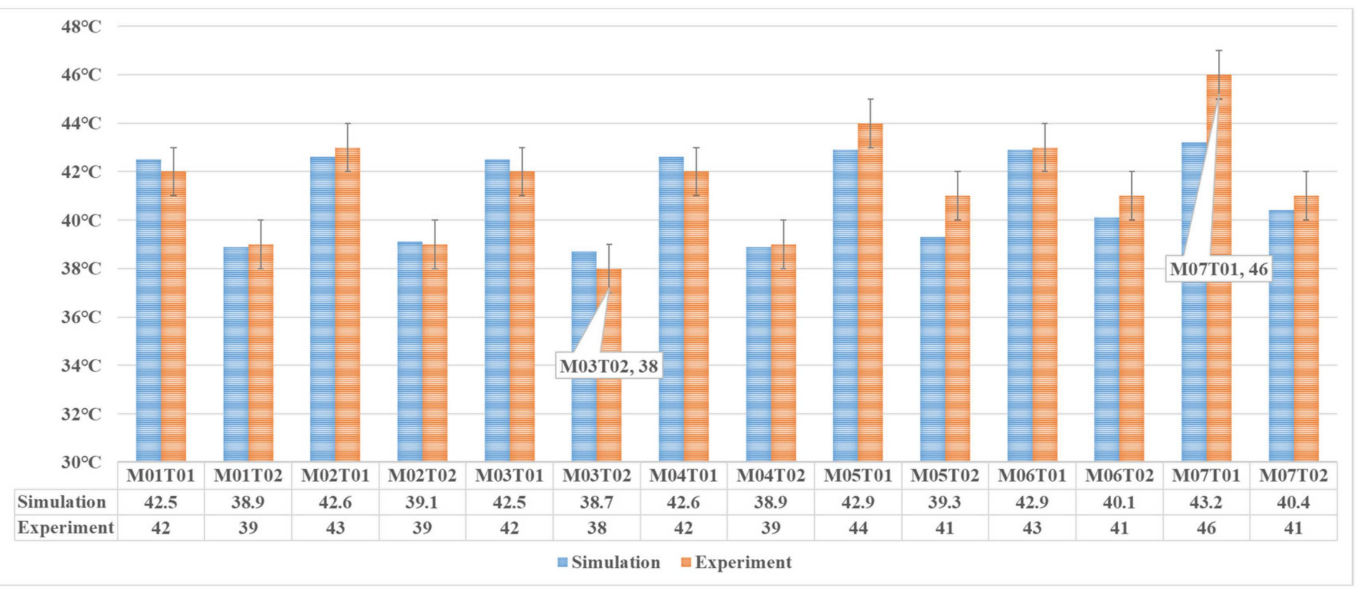

Figure 12. Temperature comparison between simulation and experiment on each temperature sensor.

From the above discussion, we can see that the results between the simulation and the experiment of the power battery pack are consistent, which verifies the accuracy and the rationality of the developed model. However, it is reported that the reference design cannot meet the standard of the thermal performance of the power battery pack. Therefore, it is necessary to improve the thermal management design scheme of the battery pack.

\section{Improvements}

\subsection{Cooling Strategy}

The purpose of the cooling strategy analysis is to provide guidance for the thermal optimization of the power battery pack to improve temperature uniformity and reduce the maximum temperature. It is generally considered that the power battery pack is insulated from the ambient environment under high-temperature conditions, and the heat it generates is mainly absorbed by the coolant. Therefore, Newton's cooling law is applicable.

$$
Q_{p a}=h_{p a} A_{p a}\left(T_{p a}-T_{c}\right)
$$

It can be seen from Equation (9) that the cooling strategy can be carried out by adjusting these four variables: $h_{p a}$ (equivalent heat transfer coefficient of power battery pack to coolant), $A_{p a}$ (contact area between power battery pack and cold plate), $T_{p a}$ (temperature of power battery pack) and $T_{\mathcal{c}}$ (coolant 
temperature). Without changing the brand or the type of battery, $T_{p a}$ keeps the same under the same conditions, and the $T_{c}$ does not change without changing the series and the parallel structure of the liquid-cooled BTMS. Therefore, the implementation of the cooling strategy in this work mainly focuses on adjusting these two variables: $h_{p a}$ and $A_{p a}$.

In terms of the $h_{p a}$, the primary measure is to change the width of the channel or design the oblique fins in the liquid-cooled plate. This solution can promote or decrease the disturbance to the coolant and then adjust the local flow velocity of the coolant, which can correspondingly change the value of the $h_{p a}$ in the same proportion. As can be seen from Figure 10, the maximum temperature of the battery module 7 approximately reached $43.4{ }^{\circ} \mathrm{C}$ at the end of the discharge, and each battery module exhibited a temperature distribution with lower side temperature and higher intermediate temperature. From the point of view of the analysis, it is necessary to enhance the heat transfer capacity of all battery modules so as to improve the thermal performance of the pack. Therefore, compared with Figure 4, the improved cold plate structure is shown in Figure 13. The conventional straight channels are replaced by the mini-channels formed by the matrix of oblique fins. The oblique fins are equally spaced along the length of the cold plate, and the longitudinal boundary of the matrix of oblique fins is the maximum distance between the battery module. Along the width of the cold plate, the field of the oblique fins is encrypted, which is located directly below the central area of the battery module. Also, the heat exchange capacity between the coolant and the central cells in the battery module with poor heat dissipation conditions can then be enhanced, thus the heat exchange is more uniform and thorough. Besides, the thermal pads of the reference design are replaced by thermal pads with thermal conductivity of $4 \mathrm{~W} / \mathrm{m} / \mathrm{K}$ to increase the $h_{p a}$.

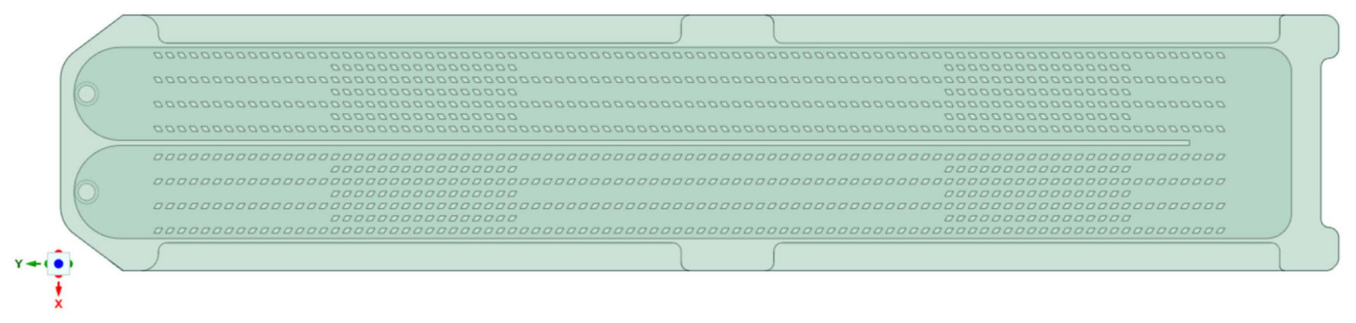

Figure 13. Outline of the improved cold plate structure.

Moreover, in terms of the $A_{p a}$, the primary measure is to change the contact area between the battery module and the cold plate, namely, change the area of the thermal pad. It is noted that the area of the thermal pad has an upper limit. Therefore, the heat dissipation capacity of the power battery pack is also limited. In the reference design, the shape of the thermal pad is shown in Figure 14a. As can be seen from Figure 12, the experimental temperatures at the edge of the battery modules 1-4 were lower than $40^{\circ} \mathrm{C}$, which caused the temperature difference of the pack to exceed $5^{\circ} \mathrm{C}$. Furthermore, as can be seen from the simulation result, the temperature at the edge of the battery module 5 was higher than the temperatures at the edge of the battery modules $1-4$ but still below $40{ }^{\circ} \mathrm{C}$. From the point of view of the analysis, it is necessary to weaken the heat dissipation capability of both sides of the battery modules $1-5$ so as to maintain good temperature uniformity. Therefore, the thermal pads placed under the battery modules $1-4$ are adjusted from Figure $14 a, b$, and the thermal pad placed under the battery module 5 is adjusted from Figure 14a-c. 


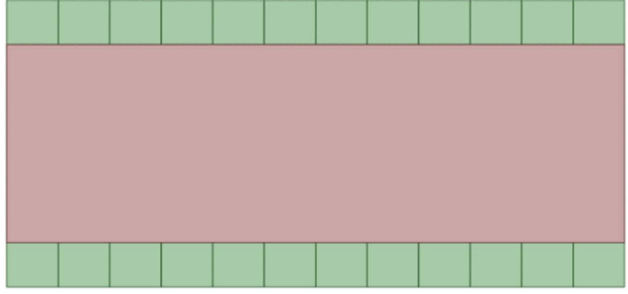

(a)

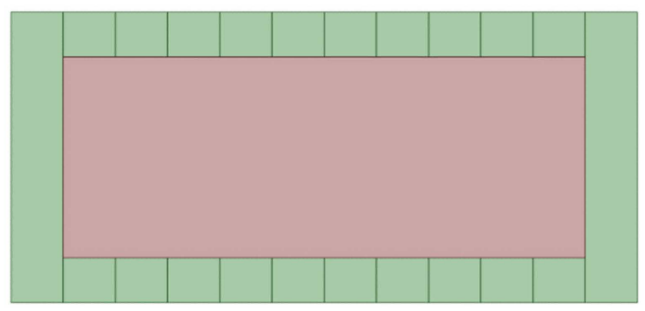

(b)

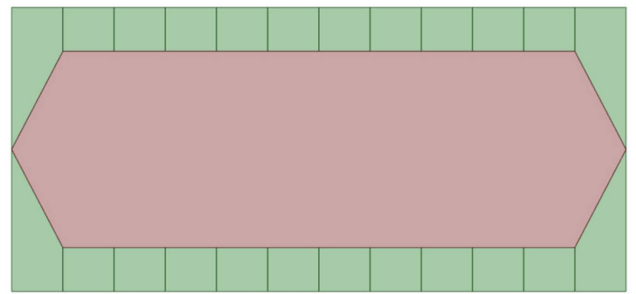

(c)

Figure 14. The shape of the thermal pad: (a) typical design; (b) shortened design; (c) sharp design.

\subsection{Analysis}

Throughout the improvement process, we performed iterative analysis of the corresponding structure based on the methodology of numerical simulation and finally reached the improved design. The temperature distributions of the power battery pack based on the improved solution are shown in Figure 15. Compared with the reference design, the maximum temperature of the power battery pack based on the improved solution was about $42.5^{\circ} \mathrm{C}$, which was nearly $1^{\circ} \mathrm{C}$ lower than the $43.4^{\circ} \mathrm{C}$ based on the reference design. The application of the cooling strategy achieved practical results-more heat was taken away by the coolant. Moreover, the minimum temperature of the power battery pack was about $30^{\circ} \mathrm{C}$, which was almost unchanged. It is reported that the specific heat capacity of the coolant was fixed, and although the overall heat dissipation of the power battery pack was increased, the coolant had minimal heat dissipation efficiency on the bottom surface of the battery module. Further observation showed that the intermediate temperature of the battery modules 1-4 was no longer significantly higher than the temperature of the battery on both sides, and the temperature distribution was more uniform than before.

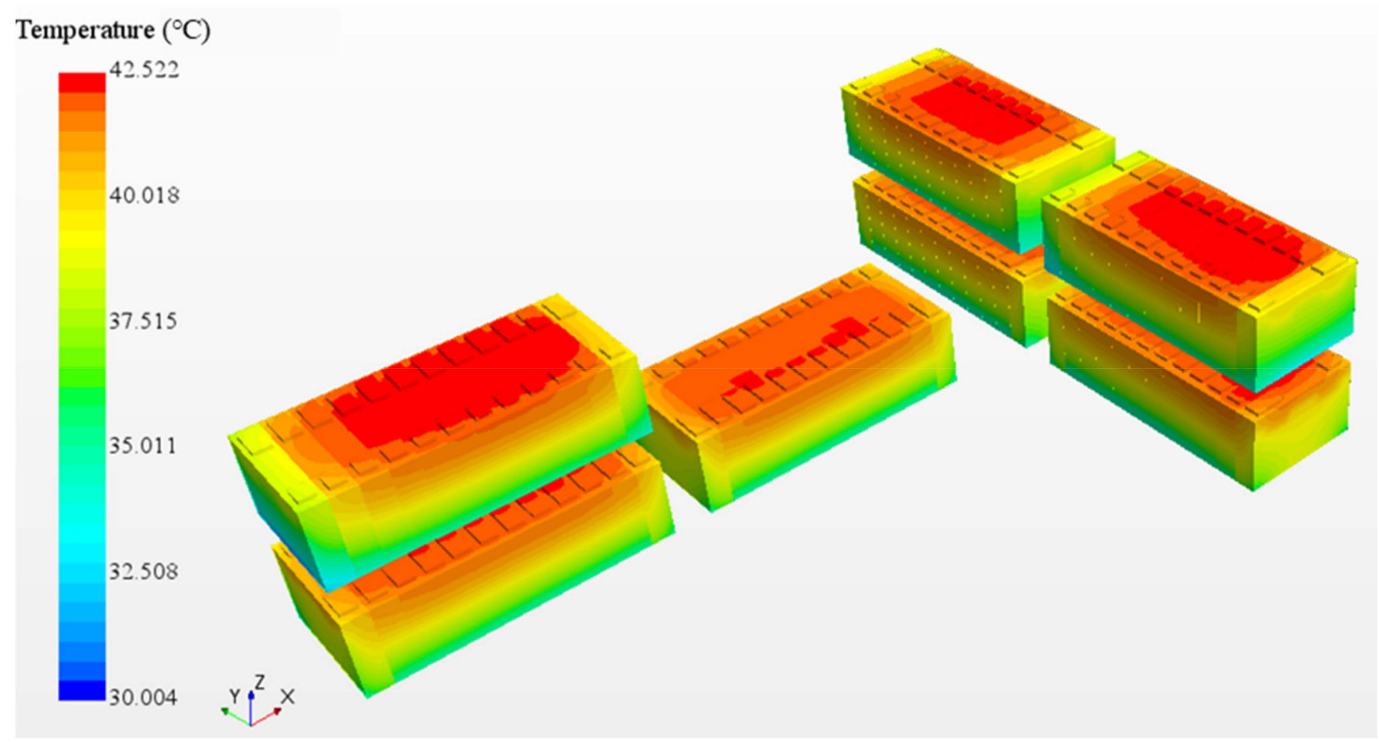

Figure 15. Temperature distributions of the power battery pack based on the improved solution. 
The temperature comparison between the reference design and the improved solution based on each temperature sensor is shown in Figure 16. Compared to the reference design, the maximum temperature based on the improved solution was $42.2^{\circ} \mathrm{C}$, which was located at the No. 1 measuring point of the battery module 7 , and the minimum temperature was $39.7^{\circ} \mathrm{C}$, which was located at the No. 2 measuring point of the battery module 5 , and the temperature difference reached $2.5^{\circ} \mathrm{C}$ after the discharge. Except for the temperature of the No. 1 measuring point of the battery module 7, which decreased by $1{ }^{\circ} \mathrm{C}$, the temperature of the No. 1 measuring point of the other battery modules decreased by $0.8^{\circ} \mathrm{C}$. The temperature of the No. 2 measuring point of the battery modules $1-4$ rose by at least $2{ }^{\circ} \mathrm{C}$, and the temperature of the No. 2 measuring point of other battery modules did not exceed $0.4^{\circ} \mathrm{C}$. Therefore, the maximum temperature of the power battery pack dropped by $1{ }^{\circ} \mathrm{C}$, and the minimum temperature rose by $1^{\circ} \mathrm{C}$. As can be seen from Figure 12, the simulation temperature was $1.7^{\circ} \mathrm{C}$ lower than the experimental value, which was located at the No. 2 measuring point of the battery module 5 . Thus, there is sufficient reason to believe that the improved solution can reach the standard of the thermal performance of the power battery pack.

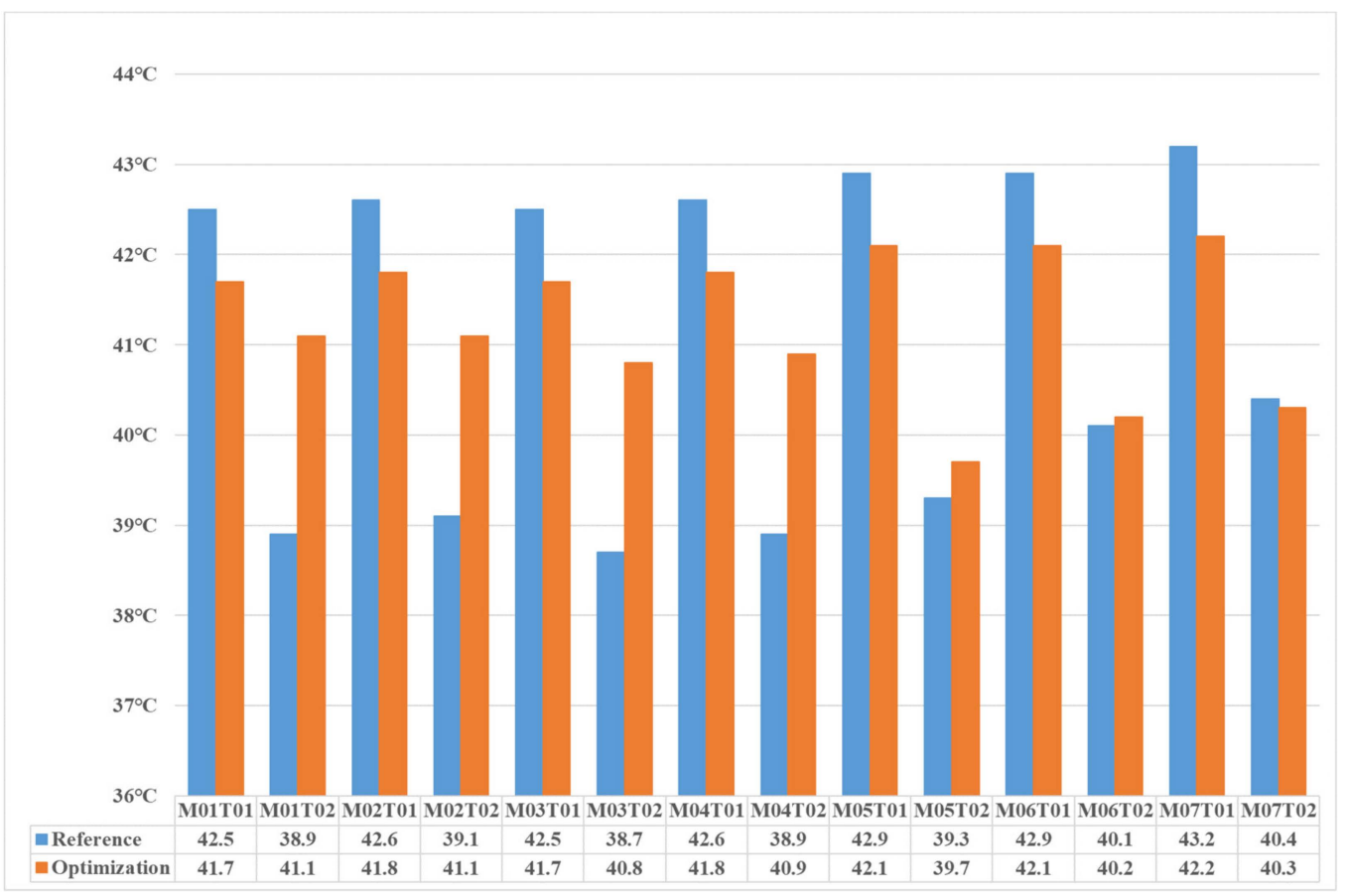

Figure 16. Temperature comparison between the reference design and the improved solution based on each temperature sensor.

\section{Conclusions}

In this paper, a novel improved design solution was introduced for a practical and typical power battery pack to enhance thermal performance and improve the temperature uniformity based on the heat dissipation strategy of liquid cooling.

At the beginning of the model development, a mathematical model describing the heat generation and the absorption procedure in the power battery pack was established. Then, a geometric model describing the boundary of the power battery pack was developed and set as a reference design. Based on the heat transfer path, the simplification of the power battery pack was carried out, and the finite element analysis model was established. At the same time, the experimental apparatus was built, which was used to measure the thermal performance of the liquid-cooled BTMS.

The consistency of the results of numerical simulation and experimental measurements verified the accuracy and the rationality of the development model. However, the reference design could not satisfy the requirement of heat dissipation. Therefore, through the analysis of the heat dissipation 
strategy, three methods were taken to solve the problems, namely: (1) designed the oblique fins in the cold plate; (2) increased the thermal conductivity of the thermal pads to $4 \mathrm{~W} / \mathrm{m} / \mathrm{K}$; (3) changed the contact area between the battery module and the cold plate.

As a result of a comparative study for the improvement and the reference design, the maximum temperature of the power battery pack dropped by $1^{\circ} \mathrm{C}$, and the temperature difference was reduced by $2^{\circ} \mathrm{C}$, which improved the thermal performance and prolonged the service life of the power battery pack. Therefore, it can be valuable guidance for the design of liquid-cooled BTMS, particularly for the power battery pack whose temperature cannot be adequately controlled by conventional methods.

However, this paper only focuses on the thermal performance of the power battery pack without considering the influence of fluid pressure drop. In fact, in liquid-cooled BTMS, the liquid is driven by the pump powered by batteries, which means more electric power will be consumed in the battery due to the pressure loss, resulting in shorter mileage of vehicles. To address this trade-off issue, our future work will be focused on the joint estimation of thermal performance and pressure loss in the power battery pack. Besides, further development of the thermal model of the battery module and the corresponding detailed experiments will also be considered as our future research work.

Author Contributions: B.X. and Y.L. proposed the novel design solution and analyzed the data; R.H. and Y.Y. performed the experiments; Y.L. and W.Z. provided experimental guidance; H.W., W.W. and M.W. prepared necessary materials and equipment; Y.L. wrote the paper.

Funding: This research was funded by the Shenzhen Economic, Trade and Information Commission of Shenzhen Municipality Strategic Emerging Industries and Future Industrial Development "Innovation Chain + Industrial Chain" Project (2017) and National Natural Science Foundation of China (Grant No. 51877120).

Conflicts of Interest: The authors declare no conflict of interest.

\section{Nomenclature}

$\begin{array}{ll}\text { Symbols } & \\ A & \text { contact area }\left(\mathrm{m}^{2}\right) \\ c_{p} & \text { specific heat capacity }(\mathrm{J} / \mathrm{kg} / \mathrm{K}) \\ h & \text { convective heat transfer coefficient }\left(\mathrm{W} / \mathrm{m}^{2} / \mathrm{K}\right) \\ I & \text { current }(\mathrm{A}) \\ P & \text { pressure }(\mathrm{Pa}) \\ Q & \text { heat generation rate }(\mathrm{W}) \\ R & \text { electric resistance }(\Omega) \\ T & \text { temperature }\left(\mathrm{K} \text { or }{ }^{\circ} \mathrm{C}\right) \\ \Delta T & \text { temperature difference }\left(\mathrm{K} \text { or }{ }^{\circ} \mathrm{C}\right) \\ t & \text { time }(\mathrm{s}) \\ U & \text { voltage }(\mathrm{V}) \\ \mathbf{V} & \text { velocity vector }(\mathrm{m} / \mathrm{s}) \\ \text { Acronyms } & \\ \text { BTMS } & \text { battery thermal management system } \\ \text { CFD } & \text { computational fluid dynamics } \\ \text { EVs } & \text { electric vehicles } \\ \text { LIBs } & \text { Lithium-ion batteries } \\ \text { NCM } & \text { Nickel-Cobalt-Manganite } \\ \text { Re } & \text { Reynolds number }\end{array}$

$\begin{array}{ll}\text { Subscript } & \\ \mathrm{a} & \text { air or ambient } \\ \mathrm{b} & \text { battery } \\ \mathrm{c} & \text { coolant } \\ \mathrm{g} & \text { generation } \\ \mathrm{j} & \text { Joule } \\ \mathrm{max} & \text { maximum value } \\ \mathrm{min} & \text { minimum value } \\ \mathrm{ocv} & \text { open circuit voltage } \\ \mathrm{p} & \text { polarization } \\ \mathrm{pa} & \text { pack } \\ \mathrm{r} & \text { reaction } \\ \mathrm{s} & \text { solid } \\ \mathrm{sr} & \text { side reaction } \\ \mathrm{t} & \text { total }\end{array}$

\section{References}

Greek symbols

$\begin{array}{ll}\rho & \text { density }\left(\mathrm{kg} / \mathrm{m}^{3}\right) \\ \mu & \text { dynamic viscosity }(\mathrm{Pa} \cdot \mathrm{s}) \\ \lambda & \text { Thermal conductivity }(\mathrm{W} / \mathrm{m} / \mathrm{K})\end{array}$

1. Thomas, C.S. Transportation options in a carbon-constrained world: Hybrids, plug-in hybrids, biofuels, fuel cell electric vehicles, and battery electric vehicles. Int. J. Hydrog. Energy 2009, 34, 9279-9296. [CrossRef]

2. Offer, G.; Howey, D.; Contestabile, M.; Clague, R.; Brandon, N. Comparative analysis of battery electric, hydrogen fuel cell and hybrid vehicles in a future sustainable road transport system. Energy Policy 2010, 38, 24-29. [CrossRef] 
3. Panchal, S.; Dincer, I.; Agelin-Chaab, M.; Fraser, R.; Fowler, M. Experimental and theoretical investigation of temperature distributions in a prismatic lithium-ion battery. Int. J. Therm. Sci. 2016, 99, 204-212. [CrossRef]

4. Broussely, M.; Herreyre, S.; Biensan, P.; Kasztejna, P.; Nechev, K.; Staniewicz, R. Aging mechanism in Li ion cells and calendar life predictions. J. Power Sources 2001, 97, 13-21. [CrossRef]

5. Wang, Q.; Jiang, B.; Li, B.; Yan, Y. A critical review of thermal management models and solutions of lithium-ion batteries for the development of pure electric vehicles. Renew. Sustain. Energy Rev. 2016, 64, 106-128. [CrossRef]

6. Deng, Y.; Feng, C.; Jiaqiang, E.; Zhu, H.; Chen, J.; Wen, M.; Yin, H. Effects of different coolants and cooling strategies on the cooling performance of the power lithium ion battery system: A review. Appl. Therm. Eng. 2018, 142, 10-29. [CrossRef]

7. Arora, S. Selection of thermal management system for modular battery packs of electric vehicles: A review of existing and emerging technologies. J. Power Sources 2018, 400, 621-640. [CrossRef]

8. Wu, W.; Wang, S.; Wu, W.; Chen, K.; Hong, S.; Lai, Y. A critical review of battery thermal performance and liquid based battery thermal management. Energy Convers. Manag. 2019, 182, 262-281. [CrossRef]

9. Xia, G.; Cao, L.; Bi, G. A review on battery thermal management in electric vehicle application. J. Power Sources 2017, 367, 90-105. [CrossRef]

10. Khan, M.; Swierczynski, M.; Kær, S. Towards an ultimate battery thermal management system: A review. Batteries 2017, 3, 9. [CrossRef]

11. Rao, Z.; Huo, Y.; Liu, X. Experimental study of an OHP-cooled thermal management system for electric vehicle power battery. Exp. Therm. Fluid Sci. 2014, 57, 20-26. [CrossRef]

12. Nithyanandam, K.; Pitchumani, R. Analysis and optimization of a latent thermal energy storage system with embedded heat pipes. Int. J. Heat Mass Transf. 2011, 54, 4596-4610. [CrossRef]

13. Nasir, F.M.; Abdullah, M.Z.; Ismail, M.A. Experimental Investigation of Water-Cooled Heat Pipes in the Thermal Management of Lithium-Ion EV Batteries. Arab. J. Sci. Eng. 2019, 44, 7541-7552. [CrossRef]

14. Nazir, H.; Batool, M.; Osorio, F.J.B.; Isaza-Ruiz, M.; Xu, X.; Vignarooban, K.; Phelan, P.; Kannan, A.M. Recent developments in phase change materials for energy storage applications: A review. Int. J. Heat Mass Transf. 2019, 129, 491-523. [CrossRef]

15. Zou, D.; Liu, X.; He, R.; Zhu, S.; Bao, J.; Guo, J.; Hu, Z.; Wang, B. Preparation of a novel composite phase change material (PCM) and its locally enhanced heat transfer for power battery module. Energy Convers. Manag. 2019, 180, 1196-1202. [CrossRef]

16. Koyama, R.; Arai, Y.; Yamauchi, Y.; Takeya, S.; Endo, F.; Hotta, A.; Ohmura, R. Thermophysical properties of trimethylolethane (TME) hydrate as phase change material for cooling lithium-ion battery in electric vehicle. J. Power Sources 2019, 427, 70-76. [CrossRef]

17. Zhao, D.; Tan, G. A review of thermoelectric cooling: Materials, modeling and applications. Appl. Therm. Eng. 2014, 66, 15-24. [CrossRef]

18. Siddique, A.R.M.; Mahmud, S.; Van Heyst, B. A comprehensive review on a passive (phase change materials) and an active (thermoelectric cooler) battery thermal management system and their limitations. J. Power Sources 2018, 401, 224-237. [CrossRef]

19. Li, X.; Zhong, Z.; Luo, J.; Wang, Z.; Yuan, W.; Zhang, G.; Yang, C.; Yang, C. Experimental Investigation on a Thermoelectric Cooler for Thermal Management of a Lithium-Ion Battery Module. Int. J. Photoenergy 2019, 2019. [CrossRef]

20. Liu, Z.; Wang, Y.; Zhang, J.; Liu, Z. Shortcut computation for the thermal management of a large air-cooled battery pack. Appl. Therm. Eng. 2014, 66, 445-452. [CrossRef]

21. Park, H. A design of air flow configuration for cooling lithium ion battery in hybrid electric vehicles. J. Power Sources 2013, 239, 30-36. [CrossRef]

22. Fan, L.; Khodadadi, J.M.; Pesaran, A.A. A parametric study on thermal management of an air-cooled lithium-ion battery module for plug-in hybrid electric vehicles. J. Power Sources 2013, 238, 301-312. [CrossRef]

23. Al-Zareer, M.; Dincer, I.; Rosen, M.A. A review of novel thermal management systems for batteries. Int. J. Energy Res. 2018, 42, 3182-3205. [CrossRef]

24. Fisher, T.S. Optimal Shapes of Fully Embedded Channels for Conjugate Cooling. IEEE Trans. Adv. Packag. 2001, 24, 555-562. [CrossRef] 
25. Yu, S.H.; Sohn, S.; Nam, J.H.; Kim, C.J. Numerical study to examine the performance of multi-pass serpentine flow-fields for cooling plates in polymer electrolyte membrane fuel cells. J. Power Sources 2009, 194, 697-703. [CrossRef]

26. Huo, Y.; Rao, Z.; Liu, X.; Zhao, J. Investigation of power battery thermal management by using mini-channel cold plate. Energy Convers. Manag. 2015, 89, 387-395. [CrossRef]

27. Chung, Y.; Kim, M.S. Thermal analysis and pack level design of battery thermal management system with liquid cooling for electric vehicles. Energy Convers. Manag. 2019, 196, 105-116. [CrossRef]

28. Tang, A.; Li, J.; Lou, L.; Shan, C.; Yuan, X. Optimization design and numerical study on water cooling structure for power lithium battery pack. Appl. Therm. Eng. 2019, 159, 113760. [CrossRef]

29. Yeow, K.; Teng, H.; Thelliez, M.; Tan, E. Thermal analysis of a Li-ion battery system with indirect liquid cooling using finite element analysis approach. SAE Int. J. Altern. Powertrains 2012, 1, 65-78. [CrossRef]

30. Sato, N. Thermal behavior analysis of lithium-ion batteries for electric and hybrid vehicles. J. Power Sources 2001, 99, 70-77. [CrossRef]

31. Bernardi, D.; Pawlikowski, E.; Newman, J. A general energy balance for battery systems. J. Electrochem. Soc. 1985, 132, 5-12. [CrossRef]

(C) 2019 by the authors. Licensee MDPI, Basel, Switzerland. This article is an open access article distributed under the terms and conditions of the Creative Commons Attribution (CC BY) license (http://creativecommons.org/licenses/by/4.0/). 